\title{
Analisis Penggunaan Modal Kerja dalam Meningkatkan Laba PT Handjaya Mandala Sampoerna Tbk di BEI
}

\author{
Riska ${ }^{1}$, Emma Lilianti ${ }^{2}$, Rismansyah ${ }^{3}$ \\ ${ }^{1}$ Fakultas Ekonomi Universitas PGRI Palembang \\ ${ }^{2}$ Fakultas Ekonomi Universitas PGRI Palembang, emmaliliantie@univpgri-palembang.ac.id \\ ${ }^{3}$ Fakultas Ekonomi Universitas PGRI Palembang, rismansyah1972@gmail.com
}

\begin{abstract}
This study aims to determine how the analysis of the use of working capital in increasing profit at PT. Handjaya Mandala Sampoerna Tbk, which is listed on the Indonesia Stock Exchange. The analytical method used is descriptive and comparative analysis method using working capital adequacy ratio which consists of three ratios, namely the ratio of total assets to current ratio and working capital turnover. The use of working capital in increasing the annual report profit from PT. Handjaya Mandala Sampoerna Tbk which is listed on the Indonesia Stock Exchange for the period 2015 to 2017.

The results of this study indicate that the use of working capital from 2015 to 2017 has increased each year. Report on the source and use of working capital of PT. Handjaya Mandala Sampoerna Tbk has a good source of working capital because in 2015 to 2017 the source of working capital was greater than the use of working capital. The role of the use of working capital in increasing profits shows the level of effectiveness and efficiency in maintaining the company's financial turnover can run well. Analysis of the evaluation of the adequacy of working capital, the level of changes in liquidity. Total assets showed 2,926, current ratio showed 3,616 and working capital turnover showed 2,837.
\end{abstract}

Keywords: Source, Use, Working Capital Adequacy Evaluation

\begin{abstract}
ABSTRAK
Penelitian ini bertujuan untuk mengetahui bagaimana penilaian Analisis Penggunaan Modal Kerja Dalam Meningkatkan Laba Pada PT. Handjaya Mandala Sampoerna Tbk Yang Terdaftar Di Bursa Efek Indonesia. Metode analisis yang digunakan adalah metode analisis deskriptif dan komparatif dengan menggunakan rasio kecukupan modal kerja yang terdiri dari tiga rasio yaitu rasio total assets trun rasio lancar dan perputaran modal kerja. Penggunaan modal kerja dalam meningkatkan laba laporan tahunan dari PT. Handjaya Mandala Sampoerna Tbk yang terdaftar di Bursa Efek Indonesia periode 2015 s/d 2017.

Hasil penelitian ini menunjukkan bahwa penggunaan modal kerja tahun 2015 s/d 2017 setiap tahunnya mengalami peningkatan. Laporan sumber dan penggunaan modal kerja PT. Handjaya Mandala Sampoerna Tbk memiliki sumber modal kerja yang baik karena ditahun 2015 s/d 2017 sumber modal kerjanya lebih besar dari pada penggunaan modal kerja. Peran penggunaan modal kerja dalam meningkatkan laba menunjukkan tingkat efektivitas dan efesien terjaga perputaran keuangan perusahan dapat berjalan dengan baik. Analisis evaluasi kecukupan modal kerja tingkat perubahan likuiditas. Total assets menunjukkan 2.926, rasio lancar menunjukkan 3.616 dan perputaran modal kerja menunjukkan 2.837 .
\end{abstract}

Kata Kunci : Sumber, Penggunaan, Evaluasi Kecukupan Modal Kerja.

\section{A. PENDAHULUAN}

Setiap perusahaan selalu dihadapkan dengan berbagai persoalan diantaranya masalah modal kerja, karena dalam menjalankan operasinya perusahaan selalu 
membutuhkan dana untuk pembelian bahan baku, membayar gaji upah, dan biayabiaya operasional lainnya menurut fahmi (2015:102). Dalam menjalankan operasinya setiap perusahaan baik yang berskala kecil, menengah maupun besar pada umumnya didirikan tujuan yaitu untuk memaksimalkan keuntungan dari perusahaan. Sehingga perusahaan dapat mempertahankan dan mengembangkan usahanya dengan lancar dan sukses, dan untuk memakmurkan para pemegang saham dan para karyawannya, para manajer perusahaan harus mampu mengantisipasi segala perubahan situasi maupun kondisi baik yang ada dalam perusahaan maupun diluar perusahaan yang dapat mempengaruhi jalannya perusahaan. Oleh karena itu, untuk dapat menghadapi perubahan yang terjadi perusahaan tentu perlu melakukan pengelolaan modal kerja yang baik agar tersedia modal yang cukup dalam melaksanakan operasi dan peningkatan usaha .

Modal kerja yang berlebihan menunjukkan adanya dana yang tidak produktif dan menimbulkan kerugian bagi perusahaan, karena dengan adanya kesempatan untuk memperoleh keuntungan telah disia-siakan sebaliknya, adanya ketidak cukupan modal kerja sangatlah mempengaruhi kegiatan perusahaan tidak dapat berjalan sebagaimana mestinya. Analisa sumber dan penggunaan modal kerja sangat penting bagi perusahaan, karena informasi modal kerja utuk menilai apakah perusahaan telah menggunakan modal kerja dengan baik dan apakah laba yang didapat sesuai dengan biaya yang dikeluarkan.

Penggunaan modal kerja dapat dilihat dari neraca laporan laba rugi dari perusahaan dengan mengetahui secara jelas perubahan yang terjadi dari neraca dan laporan perhitungan dari laba rugi, maka diharapkan pemilik dan manajer perusahaan mengetahui secara jelas perubahan dari tahun ketahun apakah perusahaan mengalami keuntungan atau kerugian dan juga dapat mengetahui laba rugi yang dialami oleh perusahaan. Laporan sumber dan penggunaan modal kerja adalah suatu laporan mengenai sumber dana yang diperoleh sebagai modal kerja dan penggunaan dalam satu periode tertentu.

\section{B. METODE PENELITIAN}

Metode penelitian yang digunakan oleh penulis adalah metode kuantitatif deskriptif dan komparatif. Melalui penelitian manusia dapat menggunakan hasilnya, secara umum data yang telah diperoleh dari penelitian dapat digunakan untuk memahami, memecahkan dan mengantisipasi masalah. Menurut Sugiyono (2011:53) metode deskriptif yaitu metode yang meliputi pengumpulan data dan penyusunan data yang telah terkumpul sebagaimana adanya tanpa bermaksud membuat kesimpulan yang berlaku secara umum. Adapun penerapan penelitian komparatif pada penetian ini ini digunakan untu mengetahui perbandingan antara perencanaan laporan keuangan yang dilakukan oleh perusahaan dengan perencaan laporan keuangan hasil penelitian ditahun 2019.

\section{1) Objek Penelitian}

Menurut Sugiyono (2011:41) merupakan sasaran ilmiah untuk mendapatkan data dengan tujuan dan kegunaan tertentu tentang suatu hal objektif, valid dan reliable tentang suatu hal (variabel tertentu). Objek penelitian ini dilakukan di PT Handjaya Mandala Sampoerna Tbkdi yang terdaftar Bursa Efek Indonesia yang diambil dari Unika Musi Charitas Palembang dengan waktu penelitian dilakukan pada bulan April 2019. 


\section{2) Variabel Penelitian}

Menurut Sugiyono (2011: 38) Variabel Penelitian adalah segala sesuatu yang berbentuk apa saja yang ditetapkan oleh peneliti untuk dipelajari kemudian ditarik kesimpulan. Pada tabel berikut ini dijelaskan definisi operasional istilah besertaindikatornya.

Tabel Definisi Operasional Variabel

\begin{tabular}{|c|c|c|c|c|}
\hline No & Variabel & Definisi & Indikator & Skala \\
\hline 1 & $\begin{array}{l}\text { Sumber } \\
\text { Modal }\end{array}$ & $\begin{array}{l}\text { Modal kerja merupakan hal yang } \\
\text { sangat penting dalam perusahaan } \\
\text { sehingga bisa dikatakan sebagai } \\
\text { nyawa dari sebuah perusahaan } \\
\text { artinya untuk menjalankan } \\
\text { kegiatannya operasinya sehari-hari } \\
\text { ataupun untuk mengadakan ivestasi } \\
\text { diperlukan modal kerja yang cukup. } \\
\text { Menurut Kasmir (2010:248) }\end{array}$ & $\begin{array}{l}\text { Berkurangnya } \\
\text { aktiva tetap. } \\
\text { Bertambahnya } \\
\text { hutang jangka } \\
\text { panjang. } \\
\text { Bertambahnya } \\
\text { modal. } \\
\text { Laba operasi }\end{array}$ & Rasio \\
\hline 2 & $\begin{array}{l}\text { Pengguna } \\
\text { an Modal } \\
\text { Kerja }\end{array}$ & $\begin{array}{l}\text { Penggunaan modal kerja dipilih dari } \\
\text { sumber modal kerja tertentu atau } \\
\text { sebaliknya. Penggunaan modal kerja } \\
\text { akan dapat mempengaruhi jumlah } \\
\text { modal kerja secara tepat, sesuai } \\
\text { dengan sasaran yang ingin dicapai } \\
\text { perusahaan. } \\
\text { Defini modal kerja adalah modal } \\
\text { yang digunakan untuk melakukan } \\
\text { kegiatan operasi perusahaan. Modal } \\
\text { kerja diartikan sebagai investasi } \\
\text { yang ditanamakan dalam aktiva } \\
\text { lancar atau akativa jangka pendek } \\
\text { seperti kas, bank, surat berharga, } \\
\text { pitung, persediaan dan aktiva lancar. } \\
\text { Menurut Kasmir (2010:222) }\end{array}$ & $\begin{array}{l}\text { Bertambahnya } \\
\text { aktiva tetap. } \\
\text { Berkurangnya } \\
\text { hutang jangka } \\
\text { panjang. } \\
\text { Berkurangnya } \\
\text { modal. } \\
\text { Rugi operasi. } \\
\text { Pembayaran } \\
\text { deviden. }\end{array}$ & Rasio \\
\hline
\end{tabular}

\section{3) Populasi dan Sampel}

Menurut Sugiyono (2011: 80) Populasi adalah kumpulan dari seluruh wilayah elemen sejenis tetapi dapat dibedakan satu sama lain karena karakteristiknya. Adapun populasi dalam penelitian ini adalah laporan keuangan dari PT. Handjaya Mandala Sampoerna Tbk Sampel adalah bagian dari jumlah dan karakteristik yang dimiliki oleh populasi tersebut. Sampel juga bagian dari populasiadapun sampel yang diambil dalam penelitian ini yaitu data laporan keuangan pada PT. Handjaya Mandala Sampoerna Tbk di Bursa Efek Indonesia dari tahun 2015 s/d 2017. Dalam penelitian ini hanya menggunakan data sekunder berupa laporan keuangan yaitu laporan keuangan per tahun selama 3tahun berturut-turut dari tahun $2015 \mathrm{~s} / \mathrm{d}$ 2017yang telah dipublikasikan oleh Bursa Efek Indonesia (BEI).

\section{4) Teknik Analisis Data}

Menurut Sugiyono (2011:243) analisis data adalah cara untuk mengelola data menjadi informasi sehingga karakteristik data tersebut mudah dipahami dan juga bermanfaat untuk menemukan permasalahan dalam sebuah penelitian. Teknik 
analisis data yang digunakan adalah metode deskriptif kuantitatif dan komparatif menganalisis laporankeuangan sumber dan penggunaan modal kerja yang telah dipublikasikan oleh Bursa Efek Indonesia (BEI).

1. Analisis Perbandingan Laporan Keuangan

2. Analisis Perbandingan Laporan Sumber Dan Penggunaan Modal Kerja

3. Evaluasi Rasio likuiditas yang digunakan perusahaan untuk mengukur kemampuan ada tiga jenis rasio yaitu :

a. Rasio total assets turn over dimana : Total assets turn over $=\frac{\text { Penjualan }}{\text { Total Asset }}$

b. Rasio lancar dimana :

Current ratio $=\frac{\text { Aktiva lancar }}{\text { Utang Lancar }}$

c. Perputaran modal kerja dimana

\section{HASIL PENELITIAN DAN PEMBAHASAN}

1) Analisis Data Laporan Perubahan Modal Kerja

Tujuan pokok perubahan modal kerja yaitu untuk mengetahui sebab-sebab terjadinya perubahan modal kerja selama satu periode tersebut. Modal yang disusun atas agar dua neraca saat waktu. Laporan tersebut menggambarkan perubahan untuk setiap jenis atau elemen modal kerja (perubahan masing-masing pos aktiva lanacar dan hutang lancar) dan perubahan modal kerja secara total.

Laporan perubahan modal kerja menggambarkan kenaikan atau penurunan setiap elemen aktiva lancar, hutang lancar serta perubahan total modal kerja dalam suatu periode tertentu. Berikut ini disajikan laporan perubahan modal kerja Pada PT Handjaya Mandala Sampoerna Tbk Selama Periode 2015 s/d 2017.

Tabel Neraca Perbandingan Per 31 Desember 2015 Dan 2016 (dalam jutaan rupiah)

\begin{tabular}{|c|c|c|c|c|}
\hline \multirow{2}{*}{ Pos-pos dalam Neraca } & \multirow{2}{*}{ 2015(Rp) } & \multirow{2}{*}{ 2016(Rp) } & \multicolumn{2}{|c|}{ Modal Keria } \\
\hline & & & Naik & Turun \\
\hline \multicolumn{5}{|l|}{ Aset lancer } \\
\hline Kas dan setara kas & 1.718 .738 & 5.056 .183 & 3.337 .445 & \\
\hline \multicolumn{5}{|l|}{ Piutang usaha } \\
\hline - Pihak ketiga & 2.288 .676 & 3.124 .358 & 835.682 & \\
\hline - Pihak-pihak berelasi & 170.066 & 198.168 & 28.102 & \\
\hline \multicolumn{5}{|l|}{ Piutang lainnya } \\
\hline - Pihak ketiga & 124.063 & 190.079 & 66.016 & \\
\hline - Pihak-pihak berelasi & 2.144 .022 & 1.483 .815 & - & 660.207 \\
\hline $\begin{array}{l}\text { Aset keuangan jangka pendek } \\
\text { lainnya }\end{array}$ & 1.349 .701 & 1.634 .332 & 284.631 & \\
\hline Persediaan & 19.071 .523 & 19.442 .023 & 370.500 & \\
\hline \multicolumn{5}{|l|}{ Pajak dibayar dimuka } \\
\hline - Pajak penghasilan badan & 1.418 & & - & 1.418 \\
\hline - pajak lain-lain & 1.168 .354 & 974.217 & - & 194.217 \\
\hline $\begin{array}{l}\text { Uang muka pembelian } \\
\text { tembakau }\end{array}$ & 1.536 .678 & 1.377 .109 & - & 159.569 \\
\hline
\end{tabular}




\begin{tabular}{|c|c|c|c|c|}
\hline Biaya dibayar dimuka & 156.025 & 167.212 & 11.187 & \\
\hline $\begin{array}{l}\text { Aset tidak lancar kelompok } \\
\text { lepasan yang dimlikil untuk } \\
\text { dijual }\end{array}$ & 78.066 & - & - & 78.066 \\
\hline Jumlah aset lancar & 29.807 .330 & 33.647 .496 & 3.840 .166 & - \\
\hline \multicolumn{5}{|l|}{ Aset tidak lancar } \\
\hline Investasi pada entitas asosiasi & 61.789 & 62.174 & 385 & \\
\hline Properti investasi & 605.616 & 492.349 & & 20.518 \\
\hline Aset tetap & 6.281 .176 & 6.988 .323 & 614.307 & - \\
\hline Tanah untuk pengembangan & 113.729 & 114.888 & 1.159 & - \\
\hline Aset pajak tangguhan & 235.765 & 272.268 & 36.503 & - \\
\hline Goodwill & 60.423 & 60.423 & - & - \\
\hline Aset tidak lancar lainnya & 844.896 & 870.447 & 25.551 & \\
\hline Jumlah aset tidak lancar & 8.230 .394 & 8.860 .781 & 630.387 & \\
\hline JUMLAH ASET & 38.010 .724 & 42.508 .277 & 4.497 .553 & - \\
\hline \multicolumn{5}{|l|}{ Liabilitas } \\
\hline \multicolumn{5}{|l|}{ Liabilitas jangka pendek } \\
\hline \multicolumn{5}{|l|}{ Utang usaha dan lainnya } \\
\hline - Pihak ketiga & 2.313 .370 & 2.567 .887 & 254.517 & \\
\hline - pihak-pihak berelasi & 877.743 & 1.302 .730 & 424.987 & - \\
\hline \multicolumn{5}{|l|}{ Utang pajak } \\
\hline - Pajak penghasilan badan & 364.569 & 735.290 & 370.721 & - \\
\hline - Pajak lain-lain & 49.154 & 898.492 & 849.338 & \\
\hline Akrual & 238.337 & 176.838 & - & 61.499 \\
\hline \multicolumn{5}{|l|}{ Liabilitas imbalan kerja } \\
\hline - Jangka pendek & 628.781 & 691.643 & 62.862 & \\
\hline \multicolumn{5}{|l|}{ Pendapatan tangguhan } \\
\hline - Jangka pendek & 45.410 & 34.830 & - & 10.580 \\
\hline \multicolumn{5}{|l|}{ Liabilitas sewa pembiayaan } \\
\hline - Jangka pendek & 20.248 & 20.768 & 520 & \\
\hline $\begin{array}{l}\text { Liabilitas atas kelompok lepasan } \\
\text { yang dimiliki untuk dijual }\end{array}$ & 1.062 & - & - & 1.062 \\
\hline $\begin{array}{l}\text { Jumlah liabilitas jangka } \\
\text { pendek }\end{array}$ & 4.538 .674 & 6.428 .478 & 1.889 .804 & \\
\hline \multicolumn{5}{|l|}{ Liabilitas jangka panjang } \\
\hline Liabilitas imbalan kerja & 1.351 .368 & 1.806 .764 & 455.396 & \\
\hline Liabilitas sewa pembiayaan & 40.878 & 65.744 & 24.866 & \\
\hline Pendapatan tangguhan & 63.744 & 32.277 & - & 31.467 \\
\hline $\begin{array}{l}\text { Jumlah liabilitas jangka } \\
\text { panjang }\end{array}$ & 1.455 .990 & 1.904 .785 & 448.794 & \\
\hline Jumlah liabilitas & 5.994 .664 & 8.333 .263 & 2.338 .599 & \\
\hline \multicolumn{5}{|l|}{ Ekuitas } \\
\hline $\begin{array}{l}\text { Ekuitas yang dapat } \\
\text { diatribusikan kepada pemilik } \\
\text { entitas induk }\end{array}$ & & & & \\
\hline
\end{tabular}




\begin{tabular}{|l|r|r|r|r|}
\hline Modal saham & & & & \\
\hline $\begin{array}{l}\text { Modal dasar - 6.300.000.000 } \\
\text { saham biasa dengan nilai } \\
\text { nominal Rp100 (Rupiah penuh) } \\
\text { per saham modal ditempatkan } \\
\text { dan disetor penuh - } \\
\begin{array}{l}4.625 .723 .076 \text { (2015: } \\
4.383 .000 .000) \text { saham biasa }\end{array}\end{array}$ & 465.272 & 465.272 & & \\
\hline Tambahan modal disetor & 20.485 .848 & 20.466 .910 & - & 18.938 \\
\hline $\begin{array}{l}\text { Selisih kurs karena penjabaran } \\
\text { laporan keuangan }\end{array}$ & 646.518 & 646.928 & 410 & - \\
\hline Ekuitas lainnya & $(29.721)$ & $(29.721)$ & & - \\
\hline Saldo laba & & & & \\
\hline Dicadangkan & 90.000 & 95.000 & 5.000 & - \\
\hline Belum dicadangkan & 10.358 .143 & 12.530 .625 & 2.172 .482 & - \\
\hline Jumlah ekuitas & 32.016 .060 & 34.175 .014 & 2.158 .954 & - \\
\hline Jumlah liabilitas dan ekuitas & 38.010 .724 & 42.508 .277 & 4.497 .553 & - \\
\hline Sumber : Laporan Keuangan PT & & & & \\
\hline
\end{tabular}

Sumber : Laporan Keuangan PT Handjaya Mandala Sampoerna Tbk periode 2015-2016 (diolah 2019)

Dari hasil tabel diatas yang diperoleh pada tahun 2015 modal kerja perusahaan yaitu sebesar $\mathrm{Rp}$ 38.010.724. Sedangkan tahun 2016 modal kerjaperusahaan yaitu sebesar Rp 42.508.277. pada tahun 2016 perusahaan ini mengalami peningkatan yaitu sebesar Rp 4.497.553.

Tabel Neraca Perbandingan Per 31 Desember 2016 Dan 2017 (dalam jutaan rupiah)

\begin{tabular}{|c|c|c|c|c|}
\hline \multirow{2}{*}{ Pos-pos dalam Neraca } & \multirow{2}{*}{ 2016(Rp) } & \multirow{2}{*}{ 2017(Rp) } & \multicolumn{2}{|c|}{ Modal Kerja } \\
\hline & & & Naik & Turun \\
\hline \multicolumn{5}{|l|}{ Aset lancar } \\
\hline Kas dan setara kas & 5.056 .183 & 7.501 .737 & 2.445 .554 & \\
\hline \multicolumn{5}{|l|}{ Piutang usaha } \\
\hline - Pihak ketiga & 3.124 .358 & 3.375 .789 & 251.431 & \\
\hline - Pihak-pihak berelasi & 198.168 & 222.124 & 23.956 & \\
\hline \multicolumn{5}{|l|}{ Piutang lainnya } \\
\hline - Pihak ketiga & 190.079 & 180.752 & - & 9.327 \\
\hline - Pihak-pihak berelasi & 1.48 & 2.316 & - & 1.481 .499 \\
\hline $\begin{array}{l}\text { Aset keuangan jangka pendek } \\
\text { lainnya }\end{array}$ & 1.634 .332 & 2.374 .246 & 739.914 & \\
\hline Persediaan & 19.442 .023 & 18.023 .238 & - & 1.418 .785 \\
\hline Pajak dibayar dimuk & & & & \\
\hline
\end{tabular}




\begin{tabular}{|c|c|c|c|c|}
\hline - Pajak penghasilan badan & - & 81 & 81 & - \\
\hline - pajak lain-lain & 974.217 & 1.260 .002 & 285.785 & - \\
\hline $\begin{array}{l}\text { Uang muka pembelian } \\
\text { tembakau }\end{array}$ & 1.377 .109 & 1.025 .646 & - & 351.463 \\
\hline Biaya dibayar dimuka & 167.212 & 155.983 & - & 11.229 \\
\hline $\begin{array}{l}\text { Aset tidak lancara yang dimlikil } \\
\text { untuk dijual }\end{array}$ & & 58.430 & 58.430 & - \\
\hline Jumlah aset lancar & 33.647 .496 & 34.180 .353 & 532.857 & - \\
\hline \multicolumn{5}{|l|}{ Aset tidak lancar } \\
\hline Investasi pada entitas asosiasi & 62.174 & 63.382 & 1.208 & - \\
\hline Properti investasi & 492.349 & 481.322 & - & 11.027 \\
\hline Aset tetap & 6.889 .323 & 6.890 .750 & 1.427 & - \\
\hline Tanah untuk pengembangan & 114.888 & 113.954 & & 934 \\
\hline Aset pajak tangguhan & 272.268 & 333.346 & 61.078 & - \\
\hline Goodwill & 60.423 & 60.423 & - & - \\
\hline Aset tidak lancar lainnya & 870.447 & 1.017 .533 & 147.086 & - \\
\hline Jumlah aset tidak lancar & 8.860 .781 & 8.960 .710 & 99.929 & - \\
\hline JUMLAH ASET & 42.508 .277 & 43.141 .063 & 632.786 & - \\
\hline \multicolumn{5}{|l|}{ Liabilitas } \\
\hline \multicolumn{5}{|l|}{ Liabilitas jangka pendek } \\
\hline \multicolumn{5}{|l|}{ Utang usaha dan lainnya } \\
\hline - Pihak ketiga & 2.567 .887 & 2.599 .318 & 31.431 & - \\
\hline - pihak-pihak berelasi & 1.302 .730 & 1.067 .123 & - & 235.607 \\
\hline \multicolumn{5}{|l|}{ Utang pajak } \\
\hline - Pajak penghasilan badan & 735.290 & 599.688 & - & 135.602 \\
\hline - Pajak lain-lain & 898.492 & 1.268 .261 & 369.769 & - \\
\hline Akrual & 176.838 & 226.449 & 49.611 & - \\
\hline \multicolumn{5}{|l|}{ Liabilitas imbalan kerja } \\
\hline - Jangka pendek & 691.643 & 636.581 & - & 55.062 \\
\hline \multicolumn{5}{|l|}{ Pendapatan tangguhan } \\
\hline - Jangka pendek & 34.830 & 56.612 & 21.782 & - \\
\hline \multicolumn{5}{|l|}{ Liabilitas sewa pembiayaan } \\
\hline - Jangka pendek & 20.768 & 28.937 & 8.169 & - \\
\hline $\begin{array}{l}\text { Jumlah liabilitas jangka } \\
\text { pendek }\end{array}$ & 6.428 .478 & 6.482 .969 & 54.491 & - \\
\hline \multicolumn{5}{|l|}{ Liabilitas jangka panjang } \\
\hline Liabilitas imbalan kerja & 1.806 .764 & 2.239 .240 & 432.476 & - \\
\hline Liabilitas sewa pembiayaan & 65.744 & 80.530 & 14.786 & - \\
\hline Pendapatan tangguhan & 32.277 & 225.339 & 193.062 & - \\
\hline \multicolumn{5}{|l|}{$\begin{array}{l}\text { Jumlah liabilitas jangka } \\
\text { panjang }\end{array}$} \\
\hline \multicolumn{5}{|l|}{ Jumlah liabilitas } \\
\hline \multicolumn{5}{|l|}{ Ekuitas } \\
\hline \multicolumn{5}{|l|}{$\begin{array}{l}\text { Ekuitas yang dapat } \\
\text { diatribusikan kepada pemilik } \\
\text { entitas induk }\end{array}$} \\
\hline Modal saham & & & & \\
\hline
\end{tabular}




\begin{tabular}{|c|c|c|c|c|}
\hline $\begin{array}{l}\text { Modal dasar - } \\
157.500 .000 .000 \text { saham biasa } \\
\text { dengan nilai nominal Rp4 } \\
\text { (Rupiah penuh) per saham } \\
\text { modal ditempatkan dan disetor } \\
\text { penuh - } 116.318 .076 .900 \\
\text { saham biasa }\end{array}$ & 465.272 & 465.272 & - & - \\
\hline Tambahan modal disetor & 20.466 .910 & 20.449 .204 & 17.706 & - \\
\hline $\begin{array}{l}\text { Selisih kurs karena penjabaran } \\
\text { laporan keuangan }\end{array}$ & 646.928 & 646.254 & - & 674 \\
\hline Ekuitas lainnya & $(29.721)$ & $(29.721)$ & - & - \\
\hline \multicolumn{5}{|l|}{ Saldo laba } \\
\hline - Dicadangkan & 95.000 & 95.000 & - & - \\
\hline - Belum dicadangkan & 12.530 .625 & 12.486 .976 & - & 43.649 \\
\hline Jumlah ekuitas & 34.175 .014 & 34.112 .985 & - & 62.029 \\
\hline Jumlah liabilitas dan ekuitas & 42.508 .277 & 43.141 .063 & 632.786 & \\
\hline
\end{tabular}

Sumber : Laporan Keuangan PT Handjaya Mandala Sampoerna Tbk Periode 2016-2017 (diolah 2019)

Dari hasil tabel diatas yang diperoleh pada tahun 2016 modal kerja perusahaan yaitu sebesar Rp 42.508.277 dan pada tahun 2017 modal kerja perusahaan yaitu sebesar Rp 43.141.063. jadi pada tahun 2017 perusahaan ini mengalami kenaikan yaitu sebesar $\mathrm{Rp} 632.786$

Tabel PT Handjaya Mandala Sampoerna Tbk Laporan Perubahan Modal Kerja

\begin{tabular}{|l|r|r|r|r|}
\hline \multirow{2}{*}{ Pos-pos dalam Neraca } & \multirow{2}{*}{ 2015(Rp) } & \multirow{2}{*}{ 2016(Rp) } & \multicolumn{2}{|c|}{ Modal Kerja } \\
\cline { 4 - 5 } & & & \multicolumn{1}{c|}{ Naik } & \multicolumn{1}{c|}{ Turun } \\
\hline Kas & 1.718 .738 & 5.056 .183 & 3.337 .445 & - \\
\hline Piutang & 4.726 .827 & 4.996 .420 & 269.593 & - \\
\hline Persediaan & 19.071 .523 & 19.442 .023 & 370.500 & - \\
\hline Utang usaha & 3.191 .113 & 3.870 .617 & 679.504 & - \\
\hline Utang pajak & 413.723 & 1.633 .782 & 1.220 .059 & - \\
\hline Total & 29.121 .924 & 33.529 .025 & 5.877 .101 & \\
\hline Kenaikkan modal kerja & & & & \\
\hline Total & 29.121 .924 & 34.999 .025 & $\mathbf{5 . 8 7 7 . 1 0 1}$ & \\
\hline
\end{tabular}

Sumber : Laporan Keuangan PT Handjaya Mandala Sampoerna Tbk Periode 2015-2016(Diolah 2019)

Dari perubahan tabel diatas dapatlah dilihat bahwa total aktiva lancar pada tahun 2015 sebesar Rp 29.121.924 sedangkan tahun 2016 naik sebesar Rp 33.529.025. Hal tersebut menunjukkan total aktiva lancar naik menjadi Rp 5.877.101.

Tabel PT Handjaya Mandala Sampoerna Tbk Laporan Perubahan Modal Kerja Periode 31 Desember 2016 dan 2017 (dalam jutaan rupiah)

\begin{tabular}{|l|c|c|c|c|}
\hline $\begin{array}{l}\text { Pos-pos dalam } \\
\text { Neraca }\end{array}$ & \multirow{2}{*}{$\mathbf{2 0 1 6 ( R p )}$} & \multirow{2}{*}{$\mathbf{2 0 1 7 ( R p )}$} & \multicolumn{2}{|c|}{ Modal Kerja } \\
\cline { 4 - 5 } & & & Naik & Turun \\
\hline Kas & 5.056 .183 & 7.501 .737 & 2.445 .554 & \\
\hline
\end{tabular}




\begin{tabular}{|l|r|r|r|r|}
\hline Piutang & 4.996 .420 & 3.580 .990 & - & 1.415 .430 \\
\hline Persediaan & 19.442 .023 & 18.023 .238 & - & 1.418 .785 \\
\hline Utang usaha & 3.870 .617 & 3.666 .441 & - & 204.176 \\
\hline Utang pajak & 1.633 .782 & 1.867 .949 & 234.167 & \\
\hline Total & 34.999 .025 & 34.640 .355 & 2.679 .721 & 3.038 .391 \\
\hline $\begin{array}{l}\text { Selisih total } \\
\text { modal kerja }\end{array}$ & & & $\mathbf{3 5 8 . 6 7 0}$ & \\
\hline Total & $\mathbf{3 4 . 9 9 9 . 0 2 5}$ & $\mathbf{3 4 . 6 4 0 . 3 5 5}$ & $\mathbf{3 . 0 3 8 . 3 9 1}$ & $\mathbf{3 . 0 3 8 . 3 9 1}$ \\
\hline
\end{tabular}

Dari perubahan tabel diatas dapatlah dilihat bahwa total aktiva lancar pada tahun 2016 sebesar Rp 34.999.025 sedangkan tahun 2017 turun sebesar Rp 358.670. Hal tersebut menunjukkan total aktiva lancar turun menjadi Rp 358.670.

\section{Laporan Sumber Dan Penggunaan Modal Kerja}

Laporan sumber dan penggunaan modal kerja digunakan untuk mengetahui hasil-hasil aktivitas keuangan pada perusahaan dalam satu periode tertentu dan untuk melihat penyebab-penyebab terjadinya perubahan modal kerja serta untuk mengetahui dari mana sumber modal kerja diperoleh dan untuk apa modal kerja tersebut digunakan. Berikut ini laporan sumber dan penggunaan modal kerja :

Tabel PT Handjaya Mandala Sampoerna Tbk Laporan Sumber dan Penggunaan Modal Kerja Periode 31 Desember 2015 (dalam jutaan rupiah)

\begin{tabular}{|l|c|l|r|}
\hline \multicolumn{2}{|c|}{ Sumber } & \multicolumn{2}{c|}{ Penggunaan } \\
\hline Laba operasi & 13.932 .644 & $\begin{array}{l}\text { Bertambahnya } \\
\text { aktiva tetap }\end{array}$ & 8.203 .394 \\
\hline $\begin{array}{l}\text { Berkurangnya aktiva } \\
\text { tetap }\end{array}$ & 6.281 .176 & $\begin{array}{l}\text { Berkurangnya } \\
\text { hutang jangka } \\
\text { panjang }\end{array}$ & 1.351 .368 \\
\hline $\begin{array}{l}\text { Bertambahnya } \\
\text { hutang jangka } \\
\text { panjang }\end{array}$ & 1.455 .990 & Berkurangnya modal & 646.518 \\
\hline $\begin{array}{l}\text { Bertambahnya } \\
\text { modal }\end{array}$ & 465.272 & Rugi operasi & 15.844 \\
\hline & 22.135 .082 & $\begin{array}{l}\text { Pembayaran } \\
\text { deviden }\end{array}$ & 10.354 .759 \\
\hline Total & 22.135 .082 & Selisih modal kerja & 1.563 .199 \\
\hline & & 20.571 .883 \\
\hline Total & ST Handjaya Mandala Sampoerna Tbk periode 2015 (diolah 2019) \\
\hline
\end{tabular}

Tabel diatas menggambarkan laporan sumber dan penggunaan modal kerja periode 2015, dimana penggunaan modal kerja perusahaan mengalami selisih 
modal kerja sebesar Rp 1.563.199,--. Adapun sumber modal kerja pada periode ini adalah berasal dari operasi bersih sebesar Rp 13.932.644,-, berkurangnya aktiva tetap Rp 6.281.176,-, dan bertambahnya hutang jangka panjang Rp 1.455.990,-, bertambahnya modal Rp 465.272,-. Adapun penggunaan modal kerja pada periode 2015 ini yaitu pembayaran deviden Rp 10.354.759,-, bertambahnya aktva tetap Rp 8.203.394,-. Berkurangnya hutang jangka panjang $\mathrm{Rp}$ 759.206,-, berkurangnya modal Rp 646.518,-, dan rugi operasi Rp 15.844,--.

\begin{tabular}{|c|c|c|c|}
\hline \multicolumn{2}{|l|}{ Sumber } & \multicolumn{2}{|c|}{ Penggunaan } \\
\hline Laba operasi & 17.011 .447 & $\begin{array}{l}\text { Bertambahnya aktiva } \\
\text { tetap }\end{array}$ & $8 . .860 .781$ \\
\hline $\begin{array}{l}\text { Berkurangnya aktiva } \\
\text { tetap }\end{array}$ & 6.895 .483 & $\begin{array}{l}\text { Berkurangnya hutang } \\
\text { jangka panjang }\end{array}$ & 1.806 .764 \\
\hline $\begin{array}{l}\text { Bertambahnya } \\
\text { hutang jangka } \\
\text { panjang }\end{array}$ & 1.904 .785 & Berkurangnya modal & 646.928 \\
\hline \multirow[t]{2}{*}{ Bertambahnya modal } & 465.272 & Rugi operasi & 385 \\
\hline & & Pembayaran deviden & 10.352 .309 \\
\hline \multirow[t]{2}{*}{ Total } & 26.276 .987 & Total & 21.667 .167 \\
\hline & & Selisih modal kerja & 4.609 .820 \\
\hline Total & 26.276 .987 & Total & 26.276 .987 \\
\hline
\end{tabular}

\section{KESIMPULAN DAN SARAN}

1) Kesimpulan

Laba PT Handjaya Mandala Sampoerna Tbk setiap tahunnya selalu mengalami peningkatan tahun 2015 sebesar Rp 38.010.724, pada tahun 2016 sebesar Rp 42.508.277 sedangkan pada tahun 2017 sebasar $R p$ 43.141.063. Hal ini menunjukkan pengelolaan kerja yang baik. Baik dalam hal pemilihan sumber dan penggunaan modal kerjanya perusahaan sangat memperhatikan semua aspek yang memaksimalkan nilai perusahaan yaitu mendatangkan keuntungan perusahaan dimasa yang akan datang, dan dapat mempertahankan suatu kondisi sumber modal kerja lebih besar dari penggunaan modal kerjasehingga perusahaan mengalami kenaikan modal kerja ini sinyal akan memperoleh modal kerja yang cukup sehingga menunjang kelancaran operasional perusahaan. Analisis penggunaan modal kerja untuk meningkatkan laba analisis perbandingan laporan keuangan sampai dengan evaluasi rasio kecukupan modal kerja, tingkat efektivitas dan efisien terjaga sehingga dalam pengelolaan modal kerja tidak terjadi dana menganggur.

\section{2) Saran}

PT Handjaya Mandala Sampoerna terus mempertahankan pengelolaan modal kerja yang baik menunjukan tingkat perubahan meningkat, disarankan agar pihak 
manajemen senantiasa memeriksa, mengevaluasi dan mengkaji laporan sumber dan pengggunaan modal kerja sehingga hal itu dapat menjamin kinerja yang baik dimasa yang akan datang. Hal ini sebenarnya sangat menguntungkan bagi perusahaan maka sebaiknya modal kerja ini dapat digunakan seoptimal mungkin dalam mendukung kegiatan agar terus dipertahankan dan dapat mempertahankan eksistensi usahanya kedepan mengingat ketatnya persaingan usaha saat ini. Untuk meningkatkan kepercayaan pengelolaan modal kerja yang baik terhadap PT. Handjaya dengan cara menunjukkan kinerja perusahaan yang baik serta menyampaikan informasi yang cukup mengenai perkembangan perusahaan.

\section{DAFTAR PUSTAKA}

Fahmi, Irham. 2015. Pengantar Manajemen Keuangan.. Bandung: Alfabeta.

Frans, Manopo. 2016. Analisis sumber dan penggunaan modal kerja pada PT Bank Rakyat Indonesia Tbk (Persero) di Bursa Efek Indonesia. Jurnal Administrasi Bisnis. Volume 4, Nomor 2 Tahun 2016. Hal. 1- 13.

Kasmir.2017. Analisis Laporan Keuangan. Jakarta: Rajawali.

Kasmir. 2010. Pengantar Manajemen Keuangan. Jakarta: Kencana.

Munawir. 2014. AnalisaLlaporan Keuangan. Yogyakarta:Liberty.

Sugiyono. 2011. Metode Penelitian Bisnis. Bandung: Alfabeta. 